\title{
Gamma Knife radiosurgery in the treatment of abducens nerve schwannomas: a retrospective study
}

\author{
Govindaraju Lakshmi Prasad, MCh, Manish Singh Sharma, MS, MCh, Shashank S. Kale, MS, MCh, \\ Deepak Agrawal, MS, MCh, Manmohan Singh, MS, MCh, and Bhawani Shankar Sharma, MS, MCh
}

Department of Neurosurgery and Gamma Knife, All India Institute of Medical Sciences, New Delhi, India

\begin{abstract}
OBJECTIVE Of the intracranial schwannomas, those arising from the vestibular nerves are the most common. Abducens nerve (AN) schwannomas are very rare, and there is limited literature on their optimal management. Therapeutic options include surgery and/or stereotactic radiosurgery. The aim of this study was to evaluate the role of Gamma Knife radiosurgery (GKRS) in these sixth cranial nerve (CN) schwannomas.
\end{abstract}

METHODS The authors performed a retrospective analysis of patients who had undergone GKRS for intracranial tumors at their institute in the period from 2003 to 2010. Inclusion criteria were as follows: isolated AN paresis on presentation, a lesion along the course of the sixth $\mathrm{CN}$, and imaging features characteristic of a schwannoma. Patients with other $\mathrm{CN}$ deficits and neurofibromatosis Type 2 were excluded. Symptomatic improvement was defined as the resolution of or an improvement in diplopia noted on a subjective basis or as an improvement in lateral eyeball excursion noted objectively on follow-up. A reduction in tumor volume by at least $20 \%$, as noted by comparing the pre- and post-GKRS images, was deemed significant.

RESULTS Six patients with a mean age of 37.1 years (range 17-55 years) underwent primary GKRS. There were 2 prepontine cistern, 3 cavernous sinus, and 1 cisterno-cavernous tumor. The mean duration of symptoms was 6.1 months (range 3-12 months). The mean tumor volume was $3.3 \mathrm{~cm}^{3}$ (range 1.5-4.8 $\left.\mathrm{cm}^{3}\right)$. The mean tumor margin radiation dose was 12.5 Gy (range 12-14 Gy), while the median margin dose was $12 \mathrm{~Gy}$ ( $50 \%$ isodose line). The median number of isocenters used was 5 (range 4-8). The brainstem received an average 8.35-Gy radiation dosage (range 5.5-11 Gy). The mean follow-up duration was 44.3 months (range 24-78 months). Symptoms remained stable in 1 patient, improved in 3, and resolved in 2 (total improvement $83 \%$ ). Magnetic resonance imaging at the last follow-up showed a stable tumor size in 3 patients (50\%) and a reduction in the other 3 . Thus, the tumor control rate achieved was $100 \%$. No new CN deficits were noted.

CONCLUSIONS Abducens nerve schwannomas are rare intracranial tumors. They can be cavernous, cisternal, or cisterno-cavernous in location. Excellent tumor control rates and symptomatic improvement can be achieved with GKRS, which appears to be a safe and effective, minimally invasive modality for the treatment of such lesions. Therefore, it is reasonable to consider GKRS as the initial treatment of choice for this rare pathology. Long-term follow-up will be essential for further recommendations.

http://thejns.org/doi/abs/10.3171/2015.8.JNS151140

KEY WORDS Gamma Knife; stereotactic radiosurgery; sixth nerve; abducens nerve; schwannomas

I NTRACRANIAL schwannomas compose around $8 \%$ of all intracranial neoplasms. Of these, vestibular schwannomas are the most common, followed by schwannomas arising from the trigeminal and lower cranial nerves (CNs)..$^{20,28,29}$ Abducens nerve (AN) schwannomas are very rare, and to the best of our knowledge, only 34 cases have been reported to date..$^{1-8,11-14,17,19,21-26,35-38}$ Consequently, very limited literature exists for the optimal management of these tumors. Resection has potential life-threatening complications, can worsen preexisting neurological deficits, and does not guarantee total tumor removal..$^{18,30-33}$ Stereotactic radiosurgery, particularly Gamma Knife radiosurgery (GKRS), is a proven therapeutic modality, with long-term efficacy and safety demonstrated in treating the

ABBREVIATIONS AN = abducens nerve; $\mathrm{CN}=$ cranial nerve; $\mathrm{GKRS}=$ Gamma Knife radiosurgery.

SUBMITTED May 15, 2015. ACCEPTED August 19, 2015.

INCLUDE WHEN CITING Published online January 29, 2016; DOI: 10.3171/2015.8.JNS151140. 
more common vestibular schwannoma. ${ }^{10,16}$ Nevertheless, the role of radiosurgery is less well documented for AN schwannomas because of their rarity. Only 11 radiosurgically treated cases of sixth $\mathrm{CN}$ schwannomas have been reported in the literature, 10 of which were treated with GKRS, yet outcomes remain variable and poorly established for this treatment modality.,4,611,14,35 In the present study we aimed to assess the safety and effectiveness of GKRS for the primary treatment of this infrequently encountered pathology.

\section{Methods}

This retrospective study involved a detailed analysis of the records of patients treated with GKRS for intracranial tumors in the period from 2003 to 2010 at the Gamma Knife center of our national university hospital. Study inclusion criteria were as follows: isolated sixth $\mathrm{CN}$ palsy on presentation, mass lesion along the course of the involved sixth CN, and MRI findings compatible with a schwannoma (hypo- to isointense on T1-weighted images and hyperintense on T2-weighted images, with intense contrast enhancement and the absence of a dural tail). The MR images were independently assessed and approved by a neuroradiologist. Exclusion criteria were neurofibromatosis Type 2 and multiple cranial neuropathies.

\section{Radiosurgery Technique}

All patients underwent GKRS with a Leksell Model B unit. At our center, GKRS is performed on an outpatient basis, with the Leksell stereotactic frame placed after a local anesthetic is applied. After MRI studies are acquired under stereotactic conditions (1.5 T, Magnetom Sonata, Siemens), the required MR images (plain T1, T2, and contrast images) are transferred to the planning software. Leksell GammaPlan (Elekta AB) is then used to devise a plan, taking into consideration the prescription isodose, tumor margin doses, and maximal dosages, which are decided and confirmed after consulting with a radiation oncologist. Tumor volume was calculated using the following methods: in the initial years, with the equation $4 / 3 \pi r^{3}$, where $r$ is the largest measured radius of the lesion; in the later years, with dedicated GK software. A tumor margin dose of 12 Gy is conventionally used at a prescription isodose of $50 \%$ to ascertain at least $90 \%$ tumor coverage using a multi-isocenter technique. Typically, optic pathways receive no more than $8-10 \mathrm{~Gy}$, and the brainstem receives no more than $12 \mathrm{~Gy}$ of radiation dosage. All patients were discharged the same day with a prescription for oral analgesics to be taken if needed.

\section{Follow-Up}

All patients underwent serial clinical examinations and contrast MRI at the first follow-up at 6 months postprocedure and at yearly intervals thereafter. Symptomatic improvement was defined as resolution or improvement in diplopia noted subjectively or as improvement in lateral eyeball excursion (abduction) noted objectively. A reduction in tumor volume by at least $20 \%$, as noted by comparing the pre- and post-GKRS images, was deemed significant.

\section{Results}

Seven patients met the study inclusion criteria; however, 1 was lost to follow-up and thus the analysis was restricted to 6 cases ( 3 males and 3 females; Table 1). The mean age at presentation was 37.1 years (range 17-55 years). There were 4 right- and 2 left-sided tumors. All patients had isolated sixth $\mathrm{CN}$ palsy with diplopia on horizontal gaze. There were no features of other $\mathrm{CN}$ involvement. The mean duration of symptoms was 6.1 months (range 3-12 months). Three tumors were located in the cavernous sinus, 2 were in the prepontine cistern, and 1 was a cisterno-cavernous variety. Representative images are featured in Fig. 1.

All lesions were treated primarily with GKRS. The mean tumor volume was $3.3 \mathrm{~cm}^{3}$ (range $1.5-4.8 \mathrm{~cm}^{3}$ ). The mean and median margin dose delivered to the tumor was 12.5 Gy (range 12-14 Gy) and 12 Gy, respectively, at a prescription isodose of $50 \%$. The median number of isocenters used was 5 (range 4-8). The brainstem received an average 8.35-Gy radiation dose (range 5.5-11 Gy). The mean follow-up was 44.3 months (range 24-78 months). Symptoms remained stable in 1 patient $(17 \%)$, improved in $3(50 \%)$, and resolved in $2(33 \%)$. Thus, the total rate of improvement was $83 \%$. The mean time to improvement in diplopia was 12 months (range 6-24 months), and it was not related to changes in tumor volume except in a single case (Case 1). Magnetic resonance imaging at the last follow-up showed a stable tumor size in 3 patients (50\%) and a reduction in the other $3(50 \%)$. Hence, the tumor control rate achieved was $100 \%$ (Table 1). The mean time to tumor volume reduction after GKRS was 16 months (6-24 months). The relation between changes in tumor volume and duration of GKRS is graphically represented in Fig. 2. No new $\mathrm{CN}$ deficits were noted, and none of the patients had any transient increase in tumor size after radiosurgery. Small cystic changes were noted in a single case 2 years after GKRS.

\section{Discussion}

Intracranial schwannomas constitute around 8\%-10\% of all intracranial neoplasms, with vestibular schwannomas being the most common among them. ${ }^{29}$ Nonvestibular schwannomas constitute only $10 \%$ of all schwannomas and include, in descending order of frequency, those arising from the trigeminal nerve, facial nerve, and lower CNs. ${ }^{20,28}$ Schwannomas arising from the ocular motor nerves are uncommon, and AN schwannomas, in particular, are very rare. To the best of our knowledge, only 34 cases have been reported in the literature to date. ${ }^{1-8,11-14,17,19,21-26,35-38}$ The role of radiosurgery has been documented in nonvestibular schwannomas with good results ${ }^{10,16}$; however, its role in the treatment of AN schwannomas has not been well documented, with only 10 cases reported in literature (Table 2). ${ }^{4,6,11,14,35}$

Sixth CN schwannomas are typically seen in the prepontine cistern, cavernous sinus, and orbit. ${ }^{13,22,37}$ They have an equal predilection for the prepontine and cavernous sinus locations but occur more frequently in females in the 4th to 5th decade of life. The most common presentation is horizontal diplopia. Isolated sixth $\mathrm{CN}$ palsy is the 


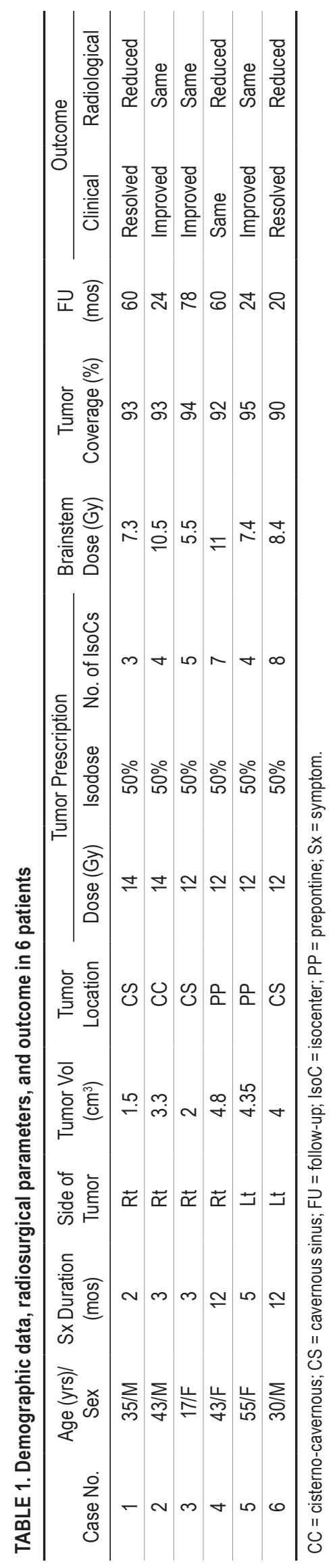

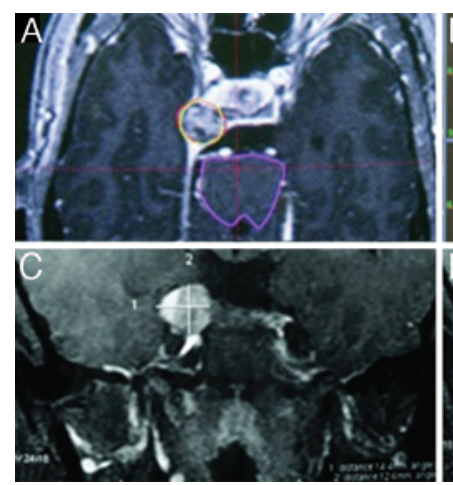

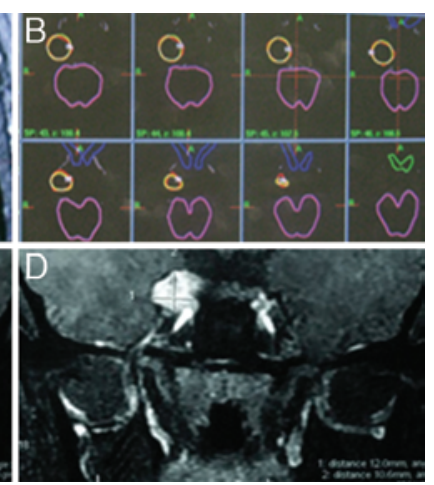

FIG. 1. Case 1. Stereotactic axial postcontrast MR image (A) revealing a right sixth $\mathrm{CN}$ schwannoma, which is segmented in red. The brainstem is outlined in magenta. The 14-Gy (50\%) isodose line, depicted in yellow, has been closely applied to the tumor margin. The GammaPlan (B) reveals the optic nerves and chiasm segmented in blue and green, respectively. Coronal contrast-enhanced MR images obtained prior to GKRS (C) and 7 months after GKRS (D), revealing a reduction in tumor size. Figure is available in color online only.

general presenting feature, though coexistent trigeminal, facial, and vestibulocochlear nerve dysfunction can also occur. Other presenting features that have been reported include headache, visual blurring, proptosis, emotional lability, and no symptoms. ${ }^{5,13,24,37}$ Tung et al. classified sixth CN schwannomas into Type I and II tumors. ${ }^{37}$ Type I tumors are associated with pure sixth $\mathrm{CN}$ palsy and are located in the cavernous sinus. Type II tumors are native to the prepontine and/or cerebellopontine cisterns and are also associated with elevated intracranial pressure due to hydrocephalus, along with adjacent $\mathrm{CN}$ dysfunction. Celli et al. added the term "cisterno-cavernous" to this classification. $^{3}$

Schwannomas are extraaxial tumors that appear isodense to gray matter on CT with intense contrast enhancement. On MRI, these tumors are typically hypo- to isointense on T1-weighted images, hyperintense on T2weighted images, and enhance intensely after contrast administration. Secondary cystic and hemorrhagic transformation is rare. ${ }^{8,9,15}$ Though the presence of isolated AN palsy helps determine the nerve of origin, associated trigeminal or trochlear nerve involvement, especially with large tumors in the cavernous sinus, can create confusion. Sixth CN schwannomas can sometimes resemble acoustic neuromas, brainstem tumors, and meningiomas.1,19,38

In our study of 6 cases, we included only those patients with isolated sixth $\mathrm{CN}$ palsy and tumors located along the course of this $\mathrm{CN}$. None of our patients had other $\mathrm{CN}$ involvement. We had 3 Type I, 2 Type II, and 1 cisternocavernous tumor (Fig. 1). On T1-weighted imaging, the lesions appeared hypo- or isointense in 3 patients each. All tumors were hyperintense on T2-weighted images and enhanced intensely after contrast administration. Secondary changes (hemorrhage, cyst formation, and necrosis) were absent.

Current treatment for intracranial schwannomas includes surgery and/or radiosurgery. Given the rarity of AN schwannomas and the consequent lack of literature, guidelines do not currently exist for the preferred manage- 


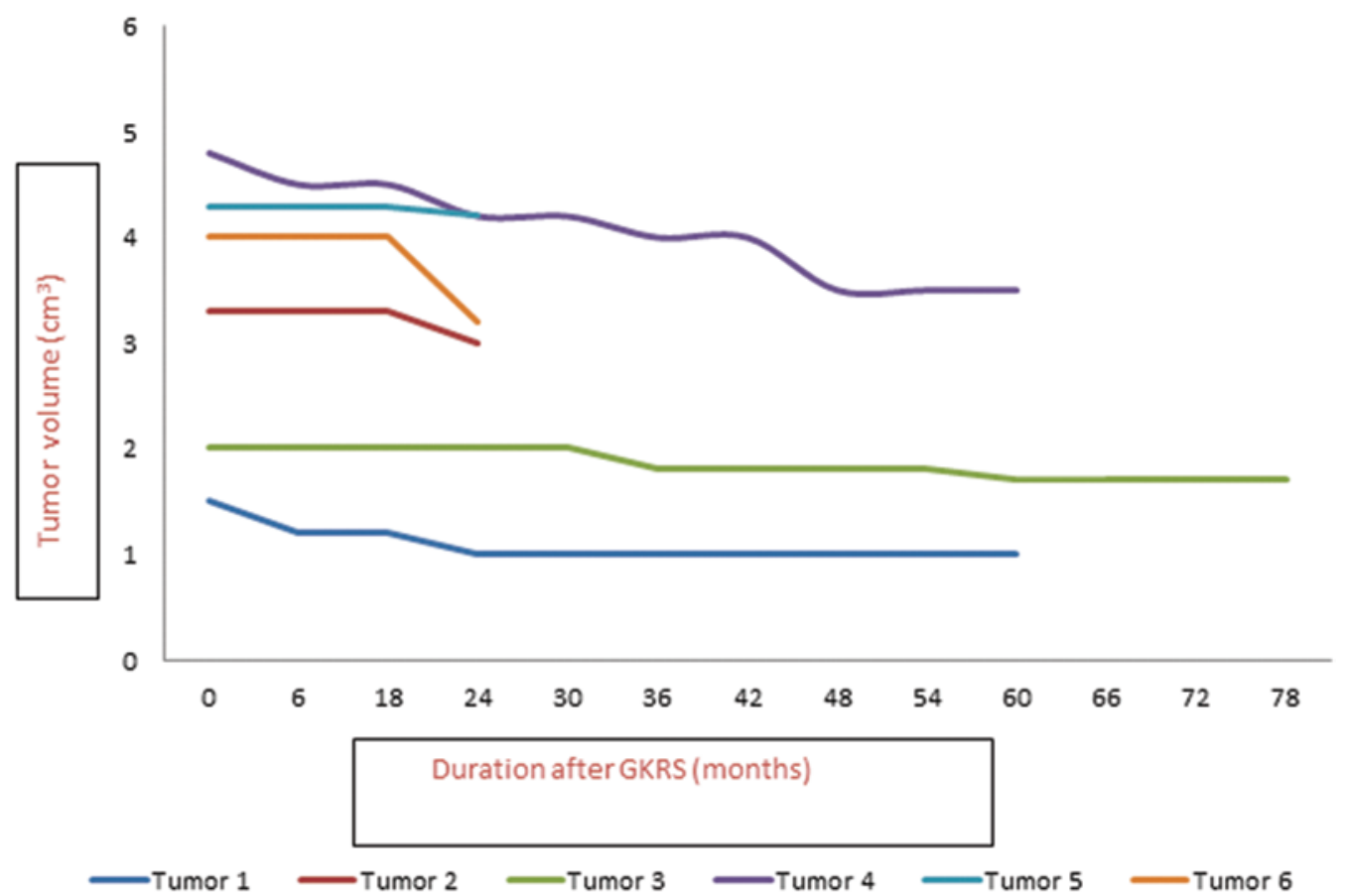

FIG. 2. Graphic presentation of initial tumor volume at the time of GKRS and the follow-up volume of each tumor as a function of time after GKRS. Separate colors have been assigned to each tumor. Figure is available in color online only.

ment. In the past, surgery through the transcavernous and subtemporal/suboccipital corridors was the only available option for Tung Type I and II tumors, respectively. Tung et al. asserted that Type II lesions were easier to remove than Type I lesions located in the cavernous sinus for evident reasons that included perioperative mortality, hemorrhage, damage to $\mathrm{CNs}$, worsening of preexisting deficits, aphasia, and motor deficits. $18,30-33,37$

Stereotactic radiosurgery is a noninvasive treatment option that involves the conformal focusing of radiation beams onto a given target and thus minimizing spill-over onto adjacent normal brain parenchyma. The modalities include GKRS, Cyber Knife, and linear accelerator (LINAC)-based platforms. Of these, GKRS is probably the most commonly used. Vestibular schwannomas are among the most common tumors to be treated using GKRS, with numerous reports documenting its safety and efficacy. ${ }^{10,16}$ Far fewer reports have documented the utility of stereotactic radiosurgery in nonvestibular schwannomas. $6,14,20,27,34,35,39$ A search of the literature revealed only 11 cases (1 LINAC and 10 GKRS) that have received stereotactic radiation as the treatment modality for AN schwannomas., ${ }^{4,6,11,14,35}$ Table 2 summarizes the available reports on GKRS for treating sixth $\mathrm{CN}$ schwannomas. Schowalter et al. reported 3 cases of AN schwannomas within their 39 cases of cranial nonvestibular schwannomas treated with GKRS. ${ }^{35}$ Although an overall tumor control rate of $95 \%$ was reported at a mean follow-up of 24 months, further details regarding the outcome of patients with AN schwannomas, in particular, were not available. Similarly, Elsharkawy et al. described 2 cases of AN schwannomas among their 36 cases of nonvestibular schwannomas treated with GKRS. An overall tumor control rate of $80 \%$ was described, but again the specific outcome within the AN schwannoma cohort was not separately analyzed. ${ }^{6}$

In a small series of oculomotor schwannomas treated with GKRS, Kim et al. described a single patient with a Type I AN schwannoma treated with a margin dose of $12.5 \mathrm{~Gy}$, with a good outcome at the 42-month follow-up. ${ }^{14}$ Hayashi et al. recently published the single largest series of AN schwannomas (4 cases) treated with GKRS. ${ }^{11}$ The tumors in all 4 of their cases were situated in the cavernous sinus, with extension into either the prepontine cistern or the orbit through the superior orbital fissure. Interestingly, only 1 of these cases had an AN palsy, whereas the others had nonspecific headache and visual impairment as the presenting symptoms. A margin dose of $12 \mathrm{~Gy}$ was delivered to the $50 \%$ isodose line in all patients. A transient increase in tumor size was observed in all cases during the 1st year with an eventual reduction in tumor volume achieved in only 2 patients at a mean follow-up of 27 months. The only patient who presented with isolated AN palsy in that series showed improvement after GKRS. The other 3 cases without preexisting AN palsy actually developed such a palsy after GKRS, which resolved in 1 case but persisted in the other 2 at the last follow-up. One patient (with the orbito-cavernous tumor type) suffered visual deterioration after the procedure. With reference to this symptom, the authors concluded that dumbbellshaped AN schwannomas should probably be treated with multistage GKRS or combined treatment modalities (microsurgery with secondary radiosurgery). In our study, the mean tumor volume was $3.3 \mathrm{~cm}^{3}$, and we found that both symptomatic stability (stable in 1, improved in 3, and resolved in 2 patients) and the tumor control rate was $100 \%$ 


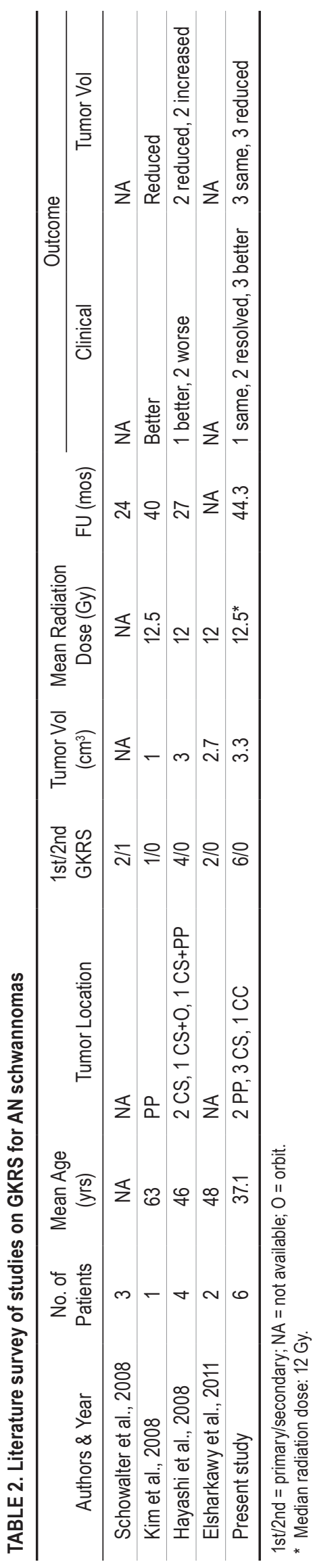

(same size in 3 and reduced in 3 patients) at a mean follow-up of 44.3 months (range 24-78 months), which is the longest follow-up duration reported to date. Moreover, no new deficits or worsening of preexisting deficits was seen in our study.

\section{Study Merits and Drawbacks}

The main drawback of this study, as in others pertaining to primary GKRS for intracranial schwannomas, is the fact that diagnosis was based purely on MRI and not on histopathological confirmation. To determine whether these schwannomas primarily originated from the sixth $\mathrm{CN}$, as opposed to a secondary involvement due to compression, remains impossible to clarify purely on an imaging basis, and this holds true for all schwannomas located elsewhere in the brain.

Nonetheless, we have tried to minimize these problems by including only those patients with isolated sixth $\mathrm{CN}$ involvement and a mass lesion located along the course of the sixth CN. Patients with neurofibromatosis Type 2 and associated $\mathrm{CN}$ deficits were excluded. This is in sharp contrast to previous studies, wherein patients with nonspecific headache and visual impairment were included and analyzed. ${ }^{6,11,14,35}$ Thus, we feel that the inclusion of only those with pure sixth $\mathrm{CN}$ palsy, the above-mentioned confounding issues will be significantly reduced.

\section{Conclusions}

Abducens nerve schwannomas are rare intracranial tumors. They can be cavernous, cisternal, or cisternocavernous in location. Excellent tumor control rates and symptomatic improvement can be achieved with GKRS, which appears to be a safe and effective, minimally invasive modality for the treatment of such lesions. Therefore, it is reasonable to consider GKRS as the initial treatment of choice for this rare pathology; however, given the available literature, caution is to be exercised when treating dumbbell-shaped tumors, especially large ones and those extending into the superior orbital fissure. Long-term follow-up is essential for further recommendations.

\section{References}

1. Acharya R, Husain S, Chhabra SS, Patir R, Bhalla S, Seghal AD: Sixth nerve schwannoma: a case report with literature review. Neurol Sci 24:74-79, 2003

2. Beppu T, Yoshida Y, Wada T, Arai H, Suzuki M, Kuroda K, et al: Trochlear and abducens nerve neurinomas accompanied by a cerebellopontine angle meningioma-case report. Neurol Med Chir (Tokyo) 37:416-421, 1997

3. Celli P, Ferrante L, Acqui M, Mastronardi L, Fortuna A, Palma L: Neurinoma of the third, fourth, and sixth cranial nerves: a survey and report of a new fourth nerve case. Surg Neurol 38:216-224, 1992

4. Chakrabarti KB, Doughty D, Plowman PN: Stereotactic multiple arc radiotherapy. II. Cranial neuroma. Br J Neurosurg 10:577-583, 1996

5. Chen BH: Neurinoma of the abducens nerve. Neurosurgery 9:64-66, 1981

6. Elsharkawy M, Xu Z, Schlesinger D, Sheehan JP: Gamma Knife surgery for nonvestibular schwannomas: radiological and clinical outcomes. J Neurosurg 116:66-72, 2012

7. Erlich SA, Tymianski M, Kiehl TR: Cellular schwannoma of 
the abducens nerve: case report and review of the literature. Clin Neurol Neurosurg 111:467-471, 2009

8. Ginsberg F, Peyster RG, Rose WS, Drapkin AJ: Sixth nerve schwannoma: MR and CT demonstration. J Comput Assist Tomogr 12:482-484, 1988

9. Hansman ML, Hoover ED, Peyster RG: Sixth nerve neuroma in the cavernous sinus: CT features. J Comput Assist Tomogr 10:1030-1032, 1986

10. Hasegawa T, Kida Y, Kobayashi T, Yoshimoto M, Mori Y, Yoshida J: Long-term outcomes in patients with vestibular schwannomas treated using gamma knife surgery: 10-year follow up. J Neurosurg 102:10-16, 2005

11. Hayashi M, Chernov M, Tamura N, Yomo S, Ochiai T, Nagai M, et al: Gamma Knife surgery for abducent nerve schwannoma. Report of 4 cases. J Neurosurg 113 Suppl:136-143, 2010

12. Ichimi K, Yoshida J, Inao S, Wakabayashi T: Abducens nerve neurinoma-case report. Neurol Med Chir (Tokyo) 37:197200, 1997

13. Irace C, Davì G, Corona $\mathrm{C}$, Candino $\mathrm{M}$, Usai S, Gambacorta M: Isolated intraorbital schwannoma arising from the abducens nerve. Acta Neurochir (Wien) 150:1209-1210, 2008

14. Kim IY, Kondziolka D, Niranjan A, Flickinger JC, Lunsford LD: Gamma Knife surgery for schwannomas originating from cranial nerves III, IV, and VI. J Neurosurg 109 Suppl:149-153, 2008

15. Kingsley DP, Brooks GB, Leung AW, Johnson MA: Acoustic neuromas: evaluation by magnetic resonance imaging. AJNR Am J Neuroradiol 6:1-5, 1985

16. Kondziolka D, Lunsford LD, McLaughlin MR, Flickinger JC: Long-term outcomes after radiosurgery for acoustic neuromas. N Engl J Med 339:1426-1433, 1998

17. Lanotte M, Giordana MT, Forni C, Pagni CA: Schwannoma of the cavernous sinus. Case report and review of the literature. J Neurosurg Sci 36:233-238, 1992

18. Lee JD, Kim SH, Song MH, Lee HK, Lee WS: Management of facial nerve schwannoma in patients with favorable facial function. Laryngoscope 117:1063-1068, 2007

19. Lo PA, Harper CG, Besser M: Intracavernous schwannoma of the abducens nerve: a review of the clinical features, radiology and pathology of an unusual case. J Clin Neurosci 8:357-360, 2001

20. Mabanta SR, Buatti JM, Friedman WA, Meeks SL, Mendenhall WM, Bova FJ: Linear accelerator radiosurgery for nonacoustic schwannomas. Int J Radiat Oncol Biol Phys 43:545-548, 1999

21. Mascarenhas L, Magalhaes Z, Honavar M, Romao H, Resende M, Resende Pereira J, et al: Schwannoma of the abducens nerve in the cavernous sinus. Acta Neurochir (Wien) 146:389-392, 2004

22. Moses JE, Vermani N, Bansal SK: Preoperative clinico-radiological diagnosis of schwannoma arising from cavernous segment of abducens nerve. Neurol India 59:471-473, 2011

23. Nakagawa T, Uchida K, Ozveren MF, Kawase T: Abducens schwannoma inside the cavernous sinus proper: case report. Surg Neurol 61:559-563, 2004

24. Nakamura M, Carvalho GA, Samii M: Abducens nerve schwannoma: a case report and review of the literature. Surg Neurol 57:183-189, 2002

25. Okada Y, Shima T, Nishida M, Okita S: Large sixth nerve neuroma involving the prepontine region: case report. Neurosurgery 40:608-610, 1997

26. Park JH, Cho YH, Kim JH, Lee JK, Kim CJ: Abducens nerve schwannoma: case report and review of the literature. Neurosurg Rev 32:375-378, 2009

27. Phi JH, Paek SH, Chung HT, Jeong SS, Park CK, Jung HW, et al: Gamma Knife surgery and trigeminal schwannoma: is it possible to preserve cranial nerve function? J Neurosurg 107:727-732, 2007
28. Pollock BE, Foote RL, Stafford SL: Stereotactic radiosurgery: the preferred management for patients with nonvestibular schwannomas? Int J Radiat Oncol Biol Phys 52:10021007,2002

29. Russell DS, Rubinstein LJ: Pathology of Tumors of the Nervous System, ed 5. London: Edward Arnold, 1989

30. Samii M, Migliori MM, Tatagiba M, Babu R: Surgical treatment of trigeminal schwannomas. J Neurosurg 82:711-718, 1995

31. Sanna M, Bacciu A, Falcioni M, Taibah A: Surgical management of jugular foramen schwannomas with hearing and facial nerve function preservation: a series of 23 cases and review of the literature. Laryngoscope 116:2191-2204, 2006

32. Sarma S, Sekhar LN, Schessel DA: Nonvestibular schwannomas of the brain: a 7-year experience. Neurosurgery 50:437-448, 438-439, 2002

33. Sharma BS, Ahmad FU, Chandra PS, Mahapatra AK: Trigeminal schwannomas: experience with 68 cases. J Clin Neurosci 15:738-743, 2008

34. Sheehan J, Yen CP, Arkha Y, Schlesinger D, Steiner L: Gamma knife surgery for trigeminal schwannoma. J Neurosurg 106:839-845, 2007

35. Showalter TN, Werner-Wasik M, Curran WJ Jr, Friedman DP, Xu X, Andrews DW: Stereotactic radiosurgery and fractionated stereotactic radiotherapy for the treatment of nonacoustic cranial nerve schwannomas. Neurosurgery 63:734-740, 2008

36. Suetake K, Kurokawa Y, Uede T, Momota H, Hashi K: A case of abducens neurinoma mimicking acoustic neurinoma. Comput Med Imaging Graph 22:257-261, 1998

37. Tung H, Chen T, Weiss MH: Sixth nerve schwannomas. Report of two cases. J Neurosurg 75:638-641, 1991

38. Vachata P, Sames M: Abducens nerve schwannoma mimicking intrinsic brainstem tumor. Acta Neurochir (Wien) 151:1281-1287, 2009

39. Zhang N, Pan L, Dai JZ, Wang BJ, Wang EM, Cai PW: Gamma knife radiosurgery for jugular foramen schwannomas. J Neurosurg 97 (5 Suppl):456-458, 2002

\section{Disclosures}

The authors report no conflict of interest concerning the materials or methods used in this study or the findings specified in this paper.

\section{Supplemental Information \\ Previous Presentations}

Portions of this work were presented as a platform presentation at the XV WFNS World Congress of Neurosurgery held in Seoul, Korea, on September 8-13, 2013.

\section{Current Affiliations}

M. S. Sharma: Department of Neurosurgery, Mayo Clinic Health System, Mankato, MN.

\section{Author Contributions}

Conception and design: Prasad. Acquisition of data: Prasad. Analysis and interpretation of data: Prasad, MS Sharma. Drafting the article: Prasad. Critically revising the article: Kale, Singh. Study supervision: Kale, Agrawal, BS Sharma.

\section{Correspondence}

Shashank S. Kale, Department of Neurosurgery and Gamma Knife, Rm. 719, CN Centre, All India Institute of Medical Sciences, Ansari Nagar, New Delhi 110029, India. email: Kale-skale67@gmail.com. 